\title{
Intellectual Property Rights, Strategic TeChnOlogy Agreements ANd MARKet Structure. The CASE OF GSM
}

\author{
by Rudi Bekkers*, Geert Duysters* and Bart Verspagen**
}

\begin{abstract}
September 2000
We thank Ed Steinmueller, Marius Meeus, participants at the the 'Swedish International Symposium on Economics, Law and Intellectual Property' (June 2000) and participants at a seminar at ECIS for helpful comments and discussion.
\end{abstract}

\section{Abstract:}

This paper investigates the role of intellectual property rights (IPRs) in shaping the GSM industry. This industry is an example of a high-tech industry in which standards play a large role. In the process of designing the GSM standard, a lot of attention has been given to IPRs, mainly to avoid a situation in which a single IPR holder could hamper or even totally block the development of the standard. Nevertheless, the ultimate GSM standard contains a large amount of so-called 'essential IPRs', i.e., IPRs without which the implementation of GSM products is impossible.

The paper starts with a general discussion of the development of GSM, and the role of firm strategy and IPRs in this process. Next, we present a database on the essential IPRs in the GSM standard. This database has been compiled on the basis of international patent statistics, and the data that manufacturers have supplied to ETSI, the European standardization body responsible for defining the GSM standard. We use this database to assess the dynamic IPR position of firms in the original GSM standard and its subsequent development.

In a next part of our analysis, we relate the firm's IPR position to the trends in strategic technology agreements in the mobile telecommunications field. We ask the question whether firms that are powerful in terms of IPRs are also the firms that are 'central' in the technology agreements network (or vice versa). We also investigate whether developments over time in the technology agreements data follow from the dynamic movements in the IPR position of a firm, and which other factors play a role in this.

Keywords: innovation strategies, strategic alliances, patents, telecommunications

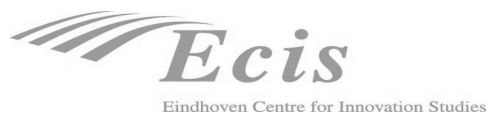

* Eindhoven Center for Innovation Studies (ECIS), Eindhoven University of Technology, PO Box 513,

NL-5600 MB Eindhoven, the Netherlands, fax +31 402474646

** ECIS and MERIT, Maastricht University

email: R.N.A.Bekkers@tue.nl, G.M.Duysters@tue.nl, bart.verspagen@merit.unimaas.nl 


\section{Introduction}

The notion of the knowledge economy implies that knowledge has become a firm's primary means of generating profits. The large body of literature on the subject (for an overview, see, e.g., Boisot, 1998) seems to point to the important conclusion that the extent to which a firm can generate and exploit economically useful knowledge depends on factors that include (strategic) management decisions as well as external factors. How these factors influence the link between (un)successful knowledge accumulation and market exploitation differs greatly between technology fields or sectors, however. It is the aim of this paper to investigate, analyze and describe this link between knowledge generation in firms and external factors in the specific context of mobile telecommunications, more specifically the development of the GSM (Global System for Mobile communications) system. ${ }^{1}$

We chose the GSM industry because it provides an example of a successful technological and market standard. With the increasingly important role of standards in the telecommunications industry (we will discuss this in more detail below), the understanding of how a successful standard can be set also becomes increasingly important. The crucial aspect in the standard setting process with regard to knowledge lies in intellectual property rights (IPRs). Especially so-called essential IPRs (without which products adhering to the standard cannot be manufactured), play an important but complicated role. Obviously, there is some tension between the private character of IPRs, and the public interest that a standard wants to foster ${ }^{2}$. As will be argued in the next section, this gives rise to a complicated process of negotiations, of which the GSM case was one of the first to take place in Europe within the information age. Drawing lessons on the relation between ownership of essential IPRs and other technology-related intangible assets thus seems to be of importance, both from a policy and scientific point of view.

\footnotetext{
${ }^{1}$ Originally, the acronym GSM stood for Groupe Spécial Mobile, named after an early group concerned with developing the standard.

${ }^{2}$ GSM has been the first case where a serious clash between IPR and standards occurred. Later, other clashes have followed, like those with the VESA local bus (VL-bus) for PC graphic cards, the MPEG2 compression standard for storing and transmitting video and audio content, with the DVD standard for storing video content and, more recently, with UMTS. For MPEG2 problems, see Iversen, 1999, p. 96. For the VESA local bus, see Bekkers \& Liotard, 1999, p. 65 and Iversen, 1999, p. 96.
} 
With multiple firms owning (essential) IPRs embodied in a standard, strategic technology alliances are of crucial importance. Holders of essential IPRs may cross-license to each other, or engage in (partly) other than licensing agreements. Firms without the access to essential IPRs may use strategic technology alliances in order to gain access to such knowledge, although they may be in a relatively bad position to do so. However, (essential) IPRs are obviously not the only factor having an impact on strategic alliances. Manufacturing capabilities, (tacit) knowledge not laid down in IPRs, or previously obtained market positions are all examples of other factors that may influence the degree to which a firm is able to attract partners.

Although relatively neglected in the traditional literature, co-operative agreements have now become an important and recurrent issue in strategic management, international business, industrial economics as well as in organization studies. Scholars in the field of innovation studies (e.g. Nooteboom, 1999; Hagedoorn and Schakenraad, 1993, Archibugi and Pianta, 1996) have observed a declining importance of large in-house R\&D laboratories, and a simultaneous increase in interfirm co-operation. However, in contrast to most other studies on technology alliances, we will argue that the value of strategic alliances can only be assessed by paying attention to the overall structure of the network in which a firm is embedded.

The research question that we are interested in with regard to the GSM industry can thus be formulated as follows. How do the ownership of essential IPRs, the position of a firm in the overall structure of the network of strategic technology alliances, and the market position of a firm interact? From the answer to this question, we are interested in drawing more general conclusions for the process of technological standardization and the relationship between technology assets and firm success in high-tech markets where standards are important.

Given the structure of the GSM market, we choose to focus on an increasing number of multinational corporations, more or less comparable in size, that link up with each other. Table 1 gives an indication of the market structure of the GSM industry. Overall, there are five players (Ericsson, Nokia, Siemens, 
Motorola and Alcatel) that dominate the market. In each of the three segments that are distinguished in Table 1, these five players hold approximately $85 \%$ of the market or more. Also, each of the five firms generally has at least a market share of $10 \%$ in each of the three segments (with only three major exceptions: Motorola in switching, Siemens in base stations and Alcatel in terminals). Other firms in the Table typically hold much smaller shares. Given the formulation of our research question above, we will attempt to provide an answer to the question how these five firms have come to dominate the market, on the basis of two major (interacting factors): the ownership of essential IPRs (as a result both of technological competencies of firms, and strategic management decisions), and the position of the firm in the network of strategic alliances.

Table 1. Estimated suppliers market share of the 33 largest GSM networks in Europe, December 1996, plus world-wide market share of GSM terminals during 1996

\begin{tabular}{lcccc} 
Supplier & $\begin{array}{c}\text { Market share } \\
\text { switching }\end{array}$ & $\begin{array}{c}\text { Market share } \\
\text { base stations }\end{array}$ & $\begin{array}{c}\text { Market share mobile } \\
\text { terminals (world-wide) }\end{array}$ & $\begin{array}{c}\text { Rank on total GSM } \\
\text { market }\end{array}$ \\
\hline Ericsson & $48 \%$ & $37 \%$ & $25 \%$ & 1 \\
Nokia & $14 \%$ & $22 \%$ & $24 \%$ & 2 \\
Siemens & $21 \%$ & $2 \%$ & $9 \%$ & 3 \\
Motorola & $1 \%$ & $13 \%$ & $20 \%$ & 4 \\
Alcatel & $10 \%$ & $10 \%$ & $6 \%$ & 5 \\
Lucent & $2 \%$ & $4 \%$ & & 6 \\
Matra & $2 \%$ & $3 \%$ & & 7 \\
Italtel & $0 \%$ & $5 \%$ & $3 \%$ & 9 \\
Nortel & $1 \%$ & $0 \%$ & & 10 \\
Philips & $0 \%$ & $2 \%$ & & 11 \\
Orbitel & $0 \%$ & $2 \%$ & & \\
\hline
\end{tabular}

Source: Bekkers \& Liotard, 1999, p. 123-124. Ranking is based on the average of all three subsystems market share, assuming that all subsystems are roughly equally important in the total sales GSM suppliers. Recent market shares are not very different from those in 1996, although Nokia seems to have won a higher share at the cost of Ericsson.

The main thread of our story is an historical overview of the GSM industry, with the process of standard setting as the most important element of this process. This history will be discussed in two parts. First, section 2 will discuss the role of IPRs in the telecommunication sector in general, and in the process of GSM standard setting in general. Given that GSM will be described as a case in this section, the broad 
history of the standard will be illustrated. Section 3 will focus on essential IPRs in GSM, by introducing some descriptive statistics from a database on essential IPRs. Given that the data on essential IPRs are firm-level data, we will illustrate the history of GSM from the point of view of individual companies in this section. Among other things, we will make a sub-division into periods: a pre-standard period that is characterized by uncertainty about future developments; a period of development of the basic standard immediately following the decision for the GSM standard; and a final period of enhancements to the standard combined with large scale diffusion of the basic technology in the market. As we will try to show, individual firm strategies with regard to R\&D and the management of (essential) IPRs are a crucial factor in shaping both the overall market structure in the industry, and the structure of the alliances network. This is the second part of our story, told in section 4 . The final section 5 will bring together the main pieces of the story and draw some general conclusions.

\section{The role of IPRs in telecommunications and GSM}

In the earliest days of the telecommunications sector, the ownership of IPRs largely determined its structure. The American Bell Telephone Company (later AT\&T) owed its dominant market position largely to the patent of Alexander Graham Bell, and also the ownership of IPRs for major inventions such as the Pupin coil and the Strowger switch turned out to be of prime importance for the success of firms (Brooks, 1975). However, after the early phase of the life cycle of the industry, the role of IPRs in the telecommunications sector waned with the emergence of the state-owned monopolist networks operators, the PTTs. This market model not only took away all effective competition between telecommunications services, but also much of the competition between the equipment suppliers in this sector. The PTTs' procurement procedures usually favoured national suppliers, and national industrial policy determined which firms received long-term supply contracts (Noam, 1992).

Research, a possible source for the generation of property rights, was not only carried out by manufacturers but also by the national operators, who all maintained extensive research laboratories. For the manufacturers, applying for IPRs had little value because it would not result in larger sales, given that 
the market was largely divided by national procurement policies. Also, manufacturers could be forced to license patents to other suppliers at no costs by operators with multi-supplier policies (see, e.g., Noam, 1992). An additional difficulty was that much of the research work of manufacturers was fully paid for by the operator, resulting in questions with regard to the ownership of the resulting IPRs. Operators, in turn, faced no competition from each other, and therefore felt little need to protect their research results. It was also in their interest that the results of their research were incorporated in the equipment they purchased.

To summarize, neither operators nor suppliers would benefit widely from protecting research results. The mutual interests of operators and suppliers did not call for comprehensive arrangements of property rights. A culture emerged in which it was considered to be improper for manufacturers to demand licensing fees to operators, and this also applied to a certain extent also to other manufacturers (see, e.g., Granstrand, 1999).

However, starting in the 1980s, competition between both network operators and equipment suppliers grew substantially. In Europe, this development was brought about by the policy of the European Community, but the liberalization of this sector was by no means restricted to the member states of the EC. In the US, the liberalization was brought about by technological developments, including that of microwave transmission. This type of transmission made it possible to build long-distance links without the need to run cables in public ground, which had been one of the foundations of the exclusive position of the incumbent network operators. This worldwide liberalization strongly increased the importance of IPRs in the telecommunication sector.

At the same time, the importance of technical standards for telecommunication system was growing. There were several reasons behind this development. First, the increasing demand for international communications required common standards to interconnect such networks. Second, the introduction of data communications between computer systems, calling for standard interfaces. This argument also applied for other services, such as fax communication. Finally, the increasing complexity of terminals and infrastructure and the growing $R \& D$ costs associated with digital systems called for economies of scale, that only could be achieved by having common standards. 
IPRs and standards obviously have a troublesome relation (Bekkers and Liotard, 1999). While it is in the interest of any party that wants to promote a standard to have the technological knowledge that is needed to implement the standard diffused widely, the main aim of IPRs, on the contrary is to restrict diffusion. The conflict is most outspoken in cases of a (semi-)public standard, when the formal standardization body will aim to give all interested parties equal access to the standards they produce. Individual firms contributing to the standard and holding IPRs on their knowledge will, on the contrary, want to enforce their exclusive rights for parts of the technologies used. Still, although IPRs and standards are often at odds with each other, they need to be combined, as was the case for GSM.

When IPRs get incorporated into a standard, two cases can be distinguished: essential and nonessential IPRs. An IPR is non-essential to the standard if other implementations are available, while if the knowledge described in an IPR is essential to the standard if it is the only way of 'doing things' while adhering to the standard. Obviously, an essential IPR for a certain standard has a great strategic value. During the phase when the standard is negotiated, such an IPR may be used as a means of blocking the standard (Granstrand, 1999). After the standard has been established, an essential IPR has great value in negotiations about the exchange of technology, or in licensing negotiations.

There are several reasons why telecommunications standards are increasingly covered by IPRs, and also by essential IPRs. In Bekkers and Liotard (1999, p. 115-116), seven of such reasons are discussed. The most important ones are (1) the high $R \& D$ investments and patent intensity in this sector, (2) the development into a truly open, world-wide market for standardized equipment, which increases the need to protect the results of research efforts, (3) telecommunications standards are most often compatibility standards, requiring that the interfaces are described in a very detailed and conscientious way, and (4) the fact that most standards are based on proposals that are developed by manufacturers. 
The strategic value of an essential IPR is especially large when there is an obligation to use the standard, and users cannot opt for alternatives. This obligatory situation is, in fact, the case for GSM. ${ }^{3}$ In such cases, owners of essential IPR know that their licenses are indispensable for anyone that wants to build products or wants to operate networks for that particular application. ${ }^{4}$ This makes it possible to demand a high fee for such licenses. Alternatively, the IPR holder could refuse monetary compensations and demand cross-licenses instead, thus gaining access to technology that might otherwise be difficult or impossible to get. A licensor could also require others to license a whole bundle of IPRs of which only a few are actually essential to the standard. Licensees have no choice but to buy the rights for this complete set. Also, the licensor could demand other types of compensations, such as the common development and/or marketing of systems. Finally, granting licenses only to a limited number of other firms could relieve the actual competition on the supply market.

Furthermore, in the telecommunications industry, strong network externalities are present, leading to very dominant standards. In some regions, the use of certain standards is even obligatory. This makes the consequences of a certain strategic behaviour possible more damaging.The first case where IPRs were of prime importance was indeed the development of the second-generation European standard for mobile telephony, called GSM. The development of this standard started around 1982. At that time, the European PTTs perceived a need for a common European standard for high-capacity mobile telephony networks. This new standard could be the successor to the various incompatible technologies that were being introduced in Europe. GSM, compared to its predecessors, would have to be an improvement in a number of ways. First, the new standard had to profit from real economies of scale (resulting in lower equipment prices) and have a large system capacity. Second, it would have to make operators less dependent on their

\footnotetext{
${ }^{3}$ The standards laid down at the European Telecommunications Standards Institute (ETSI), including GSM, are formally voluntary. Nevertheless, there are a number of reasons why European network operators have virtually no choice but to use GSM for mobile telephony networks. For example, national licenses for building such networks often refer to the GSM standard. Also, virtually all frequency bands that are allocated by the ITU for mobile telephony applications in Europe are exclusively reserved for GSM networks. Furthermore, GSM is the only secondgeneration standard for which Common Technical Regulations (CTR) are available, greatly facilitating the procedures for bringing products on the market.

${ }^{4}$ Many network operators pass on all possible risks associated with IPR infringements to their suppliers by clauses in the purchase contracts. As a result, most licenses have to be negotiated among manufacturers.
} 
suppliers by means of increased competition, and by defining not only the air-interface but also other, intra-network interfaces. Third, it would also have to support lucrative roaming services. ${ }^{5}$

The initiative for GSM was taken in the so-called Conférence Européenne des Administrations des Postes et des Télécommunications (CEPT), an organization that comprised all European incumbent telephone operators. Manufacturers initially regarded this development with fear. They dreaded the risks associated with the high development costs, and feared Japanese competition if a common standard would be defined. Network operators therefore realized that they needed to reduce the perceived uncertainties of the suppliers. Fourteen network operators then signed the so-called GSM Memorandum of Understanding (MoU), committing themselves to procure GSM networks. As a result, the reluctance of manufacturers changed into enthusiasm when the potential market size of this standard became apparent.

Research indicated that digital technology would best fulfil the capacity and cost/performance demands of the operators, although the final decision for a digital system was repeatedly postponed. Germany and France strongly subsidized the development of suitable technology, hoping to ensure a leading position for their national industry. In an attempt to create a head start for their national industries, Germany, France and Italy signed an agreement for the adoption of an identical, digital standard. This way, they were forcing the CEPT to adopt a digital standard, and they expected that such a standard would be based on one of the technologies developed by German and French suppliers.

However, actors from other countries presented technically less challenging designs that better suited networks in areas with medium traffic densities, whereas the German-French proposals were designed with high traffic densities in mind. After laborious technical discussion, comparing various proposals, the operators finally rejected the German-French proposals, and decided upon a system that was largely based on a proposal that had been submitted by Ericsson. However, this choice was difficult to accept for the governments of Germany and France, and political talks on the highest level were held to

\footnotetext{
${ }^{5}$ Roaming means that a subscriber can obtain services via guest networks (e.g., where the own network does not provide coverage, like abroad) via its own terminal. The user will be billed by her own operator for these services. Up to the mid-1990s, tariffs for international telephone traffic were much higher than actual costs. When there was
} 
prevent those two countries from stepping out from the GSM project altogether. These talks, and diplomatic arrangements between suppliers that secured that certain German and French suppliers could also play an important role in the selected technology eventually made the technology choice acceptable for these two countries.

During the period of the development of the various technical proposals, actors became increasingly aware of the imminent danger of IPRs. One of the reasons for the rejection of the GermanFrench proposal was indeed that it was considered to be 'too proprietary'. ${ }^{6}$ In 1988 , under great pressure from the EC, the GSM project was transferred from the CEPT to the newly established European Telecommunications Standards Institute (ETSI). ${ }^{7}$ ETSI aimed for a general policy concerning IPRs, but this came too late to serve the GSM project.

Aware of the risks that IPRs could constitute for them, the main European operators issued an invitation to equipment suppliers in 1988 to tender for network equipment. These operators, acting together in the GSM MoU, produced a draft procurement procedure in which manufacturers were essentially forced to give up all their IPRs and to provide for free world-wide licenses for essential patents (Garrard, 1998, p. 139, Cattaneo, 1994, p. 64, Good, 1991, p. 402, and Wilkinson, 1991, p. 97). This arrangement was found to be unacceptable by many manufacturers and resulted in a dispute that threatened the entire GSM program. Especially Motorola from the US, which was heavily involved in the development of GSM, stood up against the attempted imposition (Garrard, 1998, p. 140, Wilkinson, 1991, p. 197). Under pressure of the manufacturers, the intended provisions of the operators were dropped. However, in a Musketeer's Oath approach, a number of operators required the suppliers of their network

roaming, also mobile network could enjoy this high margin. In the late 1990s, international tariffs for fixed telephony dropped dramatically, but those for international mobile calls remained high.

${ }^{6}$ Cattaneo (1994, p. 63). It is not clear whether she refers to property rights owned by members of the SEL/Alcatel consortium, or more generally to the head start that consortium members would have if this technology was selected. Nevertheless, both situations were undesirable for other actors (see also Iversen, 1999, p.93).

${ }^{7}$ The European Community recognized that the GSM standard would greatly facilitate the strongly wished harmonization in this sector, but regarded the CEPT not as the most appropriate body to set such a standard. One reason was that the CEPT was only open for network operators, not for other actors involved in GSM such as manufacturers and candidate privately owned operators. The CEPT and its member states reacted by transferring the standardization to the ETSI: a newly established standards body that meets all the requirements of the EC. With this new body, the GSM standardization moved to a more institutionalized and more transparent environment. 
to sign a declaration in which they agreed to serve the whole GSM community, both suppliers and operators, on fair, reasonable and non-discriminatory conditions. Companies that decided not to accept this condition, as Motorola did, were not entitled to supply equipment to those operators, but thereby prevented a restriction of their rights.

In the early 1990s, however, when the first networks were being supplied to the operators, the IPRs problem peaked when Motorola refused to grant non-discriminatory licenses for its sizeable portfolio of essential patents that turned out to be essential for GSM. Motorola was only prepared to enter into a limited number of cross-licenses with selected parties, and also limited the geographic scope of such licenses to Europe. For the companies involved in these agreements, this cross-licensing reduced market risks. However, for those not involved, it created barriers to enter the market. Several companies, including Matra from France and Dancall from Denmark, made unsuccessful attempts to secure licenses. Of the many Japanese companies that showed very promising prototypes of GSM terminals around 1992, almost none succeeded to get all the necessary licenses within the first few years of commercial success of the GSM standard.

The behaviour of Motorola strongly influenced the supply market structure in the sector, but could not obstruct the success of the standard. European regulations resulted in two or more GSM operators in each EC member state, and GSM subscribers grew tremendously in all countries, especially from 1994 onwards. On the supply side, virtually all equipment was supplied by the companies that took part in the cross-licensing scheme: Ericsson, Nokia, Siemens, Alcatel, and Motorola. Many countries world-wide expressed their preference for GSM, and this forced Motorola to lift the regional restrictions in its licenses. With the use of IPRs, Motorola succeeded in having an interesting revenue stream even though it could not offer switching subsystems and even though it knew that its market prospects were restricted. With the internationalization of GSM, non-European suppliers such as Lucent (former AT\&T) and Nortel started to play a more active role, but never surpassed the success of the five champions. In the late 1990s, a number of non-European firms (especially from Japan) finally managed to obtain all the necessary licenses to build GSM terminals, but it will be difficult for them to catch up. For suppliers, the 
participation in cross-licenses turns out to be essential to obtain a strong market position. First of all, companies that do not succeed in securing all the necessary licenses simply cannot market products. It is generally held that this kept many potential Japanese and smaller European suppliers from the GSM handset market. ${ }^{8}$ This is also the case for many smaller European suppliers. ${ }^{9}$ Secondly, those firms that do succeed in getting all the necessary licenses, could be forced to pay a premium price for them. Sometimes, IPR holders are only prepared to sell a full bundle of patents that in fact only contain a few essential ones. Our own research has indicated that the cumulative fee paid for GSM handset licenses is very high, and this was recently confirmed by the actor director of the $\mathrm{ETNO}^{10}$, who revealed that royalty fees make up to $29 \%$ of the costs of GSM handset. ${ }^{11}$ Such prices make competing very difficult for those companies that are not participating in the cross-license fees.

\section{Essential patents in GSM}

Above, we have stressed the importance of essential IPRs in telecommunication standards, especially GSM. This is why we turn now to a statistical overview of essential patents in GSM. Patents are the predominant form of IPRs in telecommunication. ETSI requires its members to notify essential IPRs, and publishes these in the form of a written and electronic document that is regularly updated (ETSI, 1998). We used the ETSI list published in June 1998 to get an overview of essential patents in GSM.

The list contains 380 entries, the large majority of which are individual patents. However, companies use largely different practices in both the filing of patents and the notification to ETSI. For example, some companies apply for national patents in a few countries (usually countries with large GSM

\footnotetext{
${ }^{8}$ Cattaneo G. (1994). The making of a Pan-European network as a path-dependency process: The case of GSM versus IBC (Integrated Broadband Communications) network. In G. Pogorel (ed.). Global Telecommunications Strategies. Amsterdam: Elsevier Science, p. 68, Garrard, G.A. (1998). Cellular communications: Worldwide market development. Norwood, MA: Artech House, p. 140, and Donegan, p. (1995). A priority for the EU review (editorial). In Mobile Communications International, September/October 1995, p. 3.

${ }^{9}$ For example, one of the first companies to develop a GSM handheld phone, Dancall from Denmark, is reported to have filed a complaint with the Commission of the $\mathrm{EC}$, in a desperate attempt to eliminate its competitive disadvantages. Pelkmans, J. (1999). The GSM standard: Explaining a success story. [XX REFERENCE INCOMPLETE]

${ }^{10}$ ETNO: European public Telecommunications Network Operators' association
} 
networks), others apply for international patents (European patents or PCT applications filed either at EPO or WIPO). Some companies report only patents in Europe or the United States, others also report patents in Asian countries such as China, India and Singapore. In all of these cases, what is one invention may in fact appear as several patents, because of the filing of applications in multiple countries.

We used the EspaceNet webserver of the European Patent Office (EPO) to eliminate such 'double counts'. ${ }^{12}$ The EspaceNet database is aimed at identifying so-called patent families, which are exactly the multiple filings of one and the same invention. One may look up a patent document in the database by searching on features such as the applicant or the patent number (we mostly used the patent numbers supplied in the ETSI list). The database will supply a list of all patent documents from other patent offices (and sometimes of the same patent office) that are equivalent to the original hit. Most of the returned patent documents can then be viewed online.

In this way, we were able to reduce the 380 entries in the ETSI list to 140 patents. In the process, we decided to take into account three types of patents only in the final list: European patents, United States patents and International patents (issued with a WO number). ${ }^{13}$ The large majority of the original 380 entries can be traced back to an application in one or more of these three systems. The patents from the original list we did not include (89) were patents that were not present in the EspaceNet database (mostly patents in a few Asian countries other than Japan), or French ( 7 cases) or German (3 cases) patents that appeared not to be granted, although they had been filed a long time ago. It is our impression that most of the Asian patents are in fact covered by equivalent applications under the European or United States system, for two reasons. First, most of the titles of these Asian patents given in the ETSI database are equal to patents we identified as European, United States or international (PCT) patents. Second, patenting in a number of Asian markets only and not in the major GSM market (Europe) would not constitute sensible protection for a firm.

\footnotetext{
${ }^{11}$ 3G patent initiative devised to avoid 'Qualcomm-type' disputes. (19 June 2000). TotalTele. Retrieved 4 july 2000 from the World Wide Web: www.totaltele.com.

${ }^{12}$ We did our searches in the database during the period January 2000 - April 2000.
} 
By focusing on the three most important patent systems in the world generally, and for GSM in particular, we feel that the list of 140 patents we have is a fair representation of essential IPRs in GSM. One may argue that the ETSI essential patent database is constructed from notifications of members, and it is therefore not guaranteed that all essential patents are indeed listed in the database, neither that patents present in the database are actually essential to the standard. However, we feel that it is unlikely that a firm that holds essential IPRs in GSM would conceal these IPRs from ETSI, and that therefore the probability that there are essential patents for GSM that are not in the database is small.

Additionally, we have analyzed a version of the database that was published in July 1996. The latter database is largely restricted to the patents that are essential to what we would call 'basic GSM services', i.e., the ones that are now implemented in virtually all terminals and infrastructure. ${ }^{14}$ Patents added to this list in a later stage are usually essential only for later additions to the standard, such as the improved voice compression algorithm Enhanced Full Rate (EFR) and the packet-switched data service General Packet Radio Service (GPRS). Such new services can be optionally be implemented by manufacturers and operators.

Of the 140 patents in our database, 107 are identified by an EP number (European patents), 20 are US patents, and the remaining 13 are WO patent numbers (International patents filed under PCT). The 140 patents are held by 23 firms. Figure 1 gives an overview of the shares of these firms, where we have grouped all firms with only 1 or 2 patents under 'others'. In terms of sheer numbers, Motorola is the largest, with 27 patents. Nokia (19), Alcatel (14), Philips (13) and Telia (10) are the next largest holders of essential IPRs in GSM. It is notable that although operators clearly took the lead in the GSM development and controlled the process, they only hold a minority of the patents (BT, NTT, not shown in the figure are

\footnotetext{
${ }^{13}$ The order given in the text is also out preferred order, in the sense that if a patent has equivalents in more than one of these three systems, we will preferably note it as a European patent, than a United States patent.

${ }^{14}$ To prevent excessive delays in the standardization process, it was decided to publish those parts that are needed for basic speech services first. This standard is called GSM Phase 1. Around 1994, a number of new services was finalized including circuit-switched data, fax, and short messages. This whole set of services is what we call "basic GSM'.
} 
France Telecom, Vodafone and Nortel, who each have one patent). This is somewhat paradoxical given the usually extensive research facilities they own.

Not all firms have applied for the patents they possess by themselves. In some cases, the original applicants of the patents are subsidiaries, which may have been acquired after the original patent applications. For example, the four Ericsson patents are in fact owned (and applied for) by Orbitel, which was later acquired by Ericsson. Nokia owns patents that were originally applied for by Voicecraft (1 patent) and the University of Sherbrooke (4 patents). Philips holds patents that were applied for by Felten \& Guilleaume Fernmeldeanlagen (1 patent), and by TRT ( 1 patent). The patents owned by Bull were applied for by CP8 Transpac (in fact, these patents were also registered by CP8 Transpac at ETSI, we have assigned them to the mother company Bull).

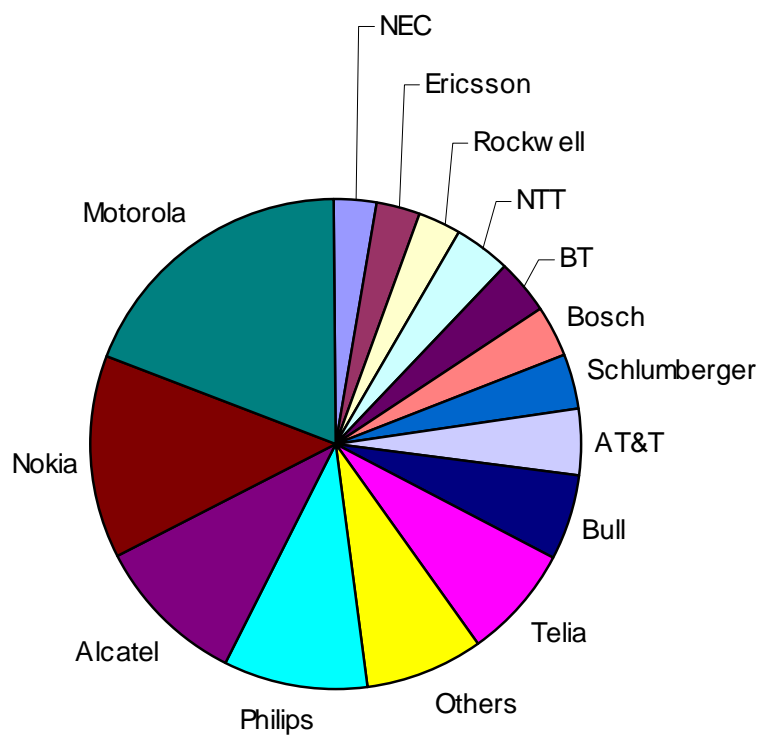

Figure 1. Shares of firms in Essential IPRs in GSM 


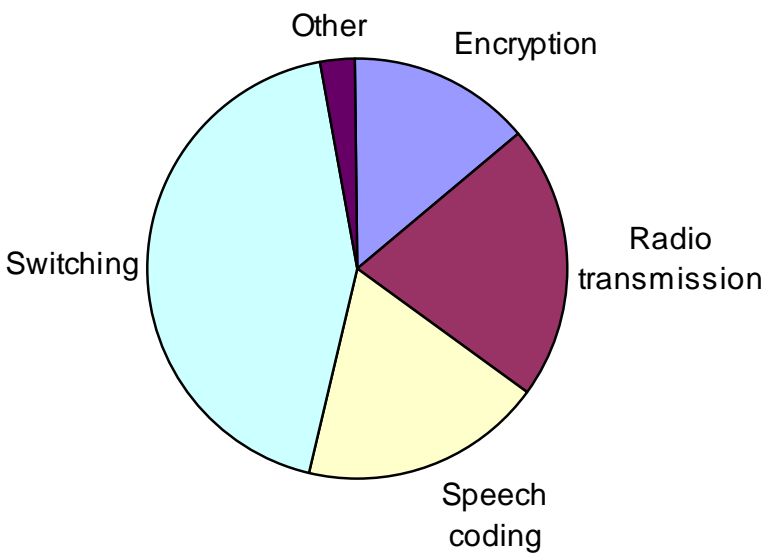

Figure 2. Shares of technical fields in Essential IPRs in GSM

On the basis of the International Patent Classes (IPC) to which the patents were assigned by the patent examiners, we have grouped the data into 5 technical fields: encryption, radio transmission, speech coding, switching, and other. Figure 2 gives the shares of these technical classes in the total amount of patents. Switching is the largest field in terms of the number of patents, with almost half of all patents (in fact, 61) in this field. The 'other' field only has 4 patents. The other three categories are roughly similar in size, with between 20 and 29 patents.

The priority dates of the 140 patents range from February 1977 to December 1997, i.e., a period of more than 20 years. In light of the history of the GSM standard that we briefly reviewed above, this period can be split into three sub periods. The first sub period runs up to the moment when the choice for the basic technology was made, i.e., February 1987. In this period, different technologies and proposals were being developed, at first without a clear vision of a European mobile communications standard, but later on clearly with such a goal in mind. The second sub period runs from February 1997 to roughly 1991. During this time span, the exact implementation of the standard was decided upon, and product 
development took place in parallel. Third, during the period after 1991, new services and other additions to the standard were developed and standardized.

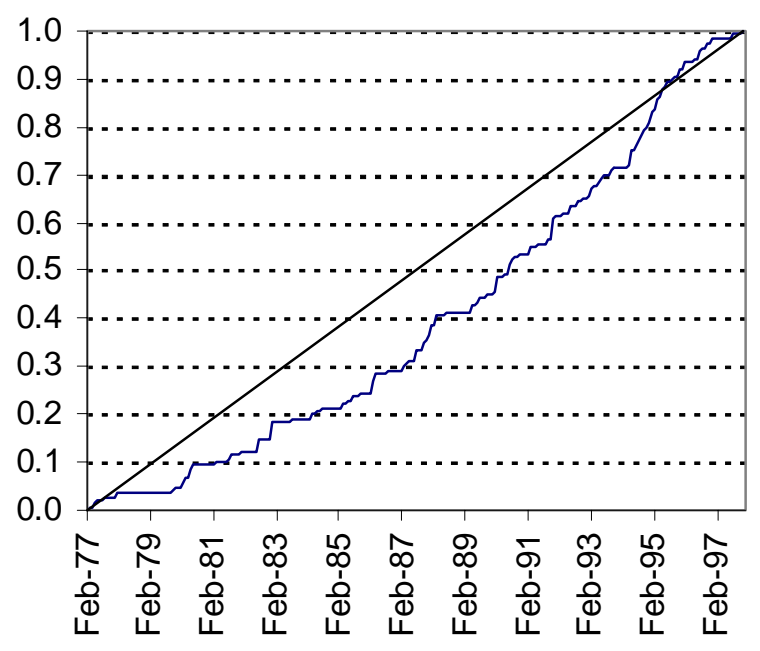

Figure 3. Cumulative share of Essential IPRs in GSM as a function of time

Figure 3 shows the total (cumulative) number of patents developed over the whole period. For almost the complete period, the line is below the 45 degrees line, which indicates that there is a tendency for the number of patents realized in a certain time period to increase over time. Generally, however, the development is quite smooth over time, with no major discontinuities that could represent sudden increases or decreases in the speed of technological change. The only point in time where one might speak of a slight increase in the rate of patenting is the period from early 1994 onwards, when somewhat of a sudden jump is seen. This can possibly be explained by the increased consciousness of firms of the value of owning essential patents, if not for the basic GSM standard, then for future, optional additions. Between 
1991 and 1993, the consequences of the rigorous patent licensing strategy of Motorola ${ }^{15}$ became apparent, as explained above. This increased the awareness of firms that it was of vital importance to secure access to essential patents, and that this could be facilitated by owning essential patents. Another factor may be the fact that with the enormous growth of GSM subscribers, the potential revenue stream of licenses became a more attractive prospect.

Figure 4 shows a similar indicator for the separate technical fields, with the exception of the small 'other' field. Several interesting issues arise from this figure. First, it is clear that encryption was the field that developed first. In fact, the inventions in this field were originally developed for a completely different field of application, i.e., bankcards, and were subsequently applied to GSM, where they were used for the Subscriber Identification Module ('SIM-card'). This explains why this field shows a strong rise of the number of essential IPRs in the early period, while the other 3 fields lag behind. Second, while developments in this field more or less flattened out after the first wave of inventions (until 1981), a strong impulse occurred from 1995 onwards. Third, developments in the other 3 fields are more or less parallel. The lines of these 3 fields are remarkably similar, and are never very wide apart. This may indeed indicate that the 3 major fields of the GSM technology developed as an intertwingled set of technology, rather than as 3 separate fields. Because new services and other parts were gradually added to the standard, it also shows that standardization work and patenting were iterative processes.

\footnotetext{
${ }^{15}$ The discussion of Motorola's strategy is based on Cattaneo, 1994; Garrard, 1998, p. 140; Hansen \& Søndergård, 1993, p. 6-7; Pelkmans, 1999; Granstrand, 1999, p. 204; Bekkers \& Liotard, 1999, Liotard, 1999 and Iversen, 1999.
} 


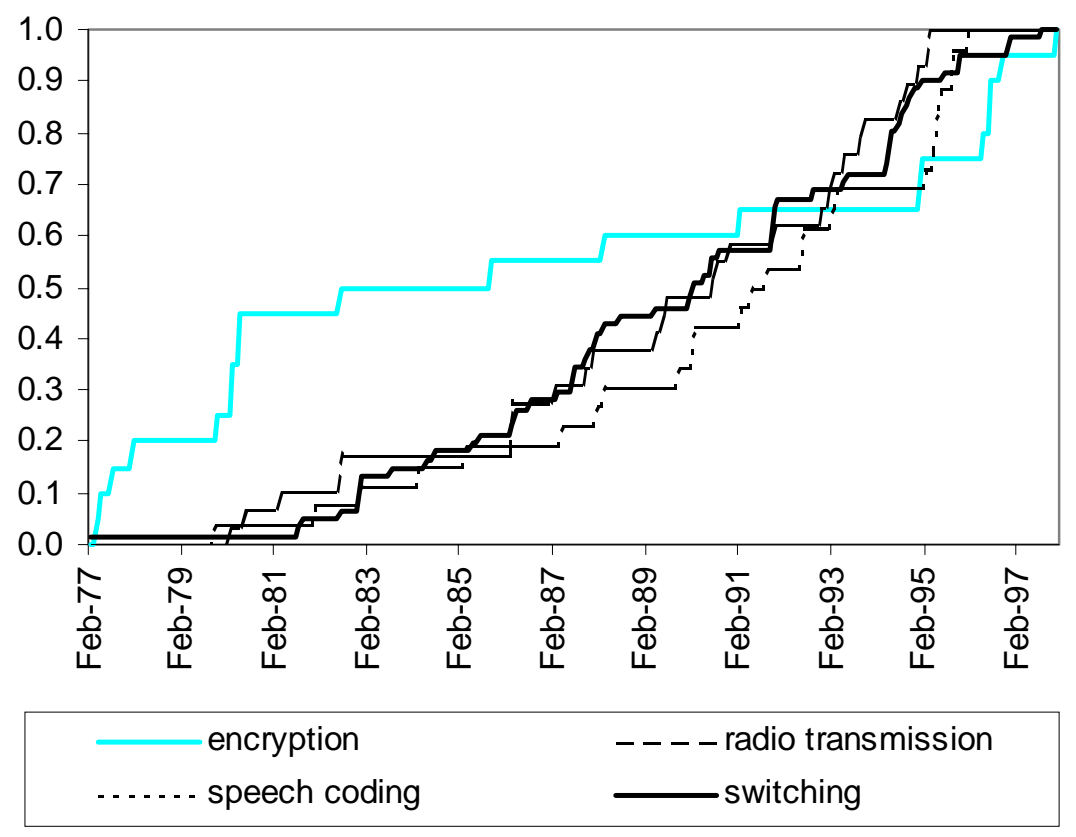

Figure 4. Cumulative share of Essential IPRs in GSM as a function of time, broken down by technical fields

The fact that the cumulative number of essential IPRs in GSM developed relatively smoothly over time does not imply that there are no differences with regard to timing between firms. Figure 5 gives an indication of this. The bars, which are displayed on the left axis, give the number of patents for each firm. The dots give the mean priority dates of the patents by the firm, where time is measured in months, and February 1977 is denoted as $1 .^{16}$ This variable is displayed on the right axis. The vertical lines that surround the dots indicate a range of plus/minus two standard deviations around the mean timing. A long (short) line thus indicates a broad (narrow) period of technical activity of the firm. The two horizontal lines in the figure indicate the subdivision into three periods that we introduced above. The part below the bottom line corresponds to the pre-standard era. The part in between the two lines refers to the period in

\footnotetext{
${ }^{16}$ A mean value of 13 would thus, for example, indicate that a firm files its patents, on average, during February 1978.
} 
which the basic choice for the standard had been made and development took place. The part above the top line refers to the period in which additional services were developed.

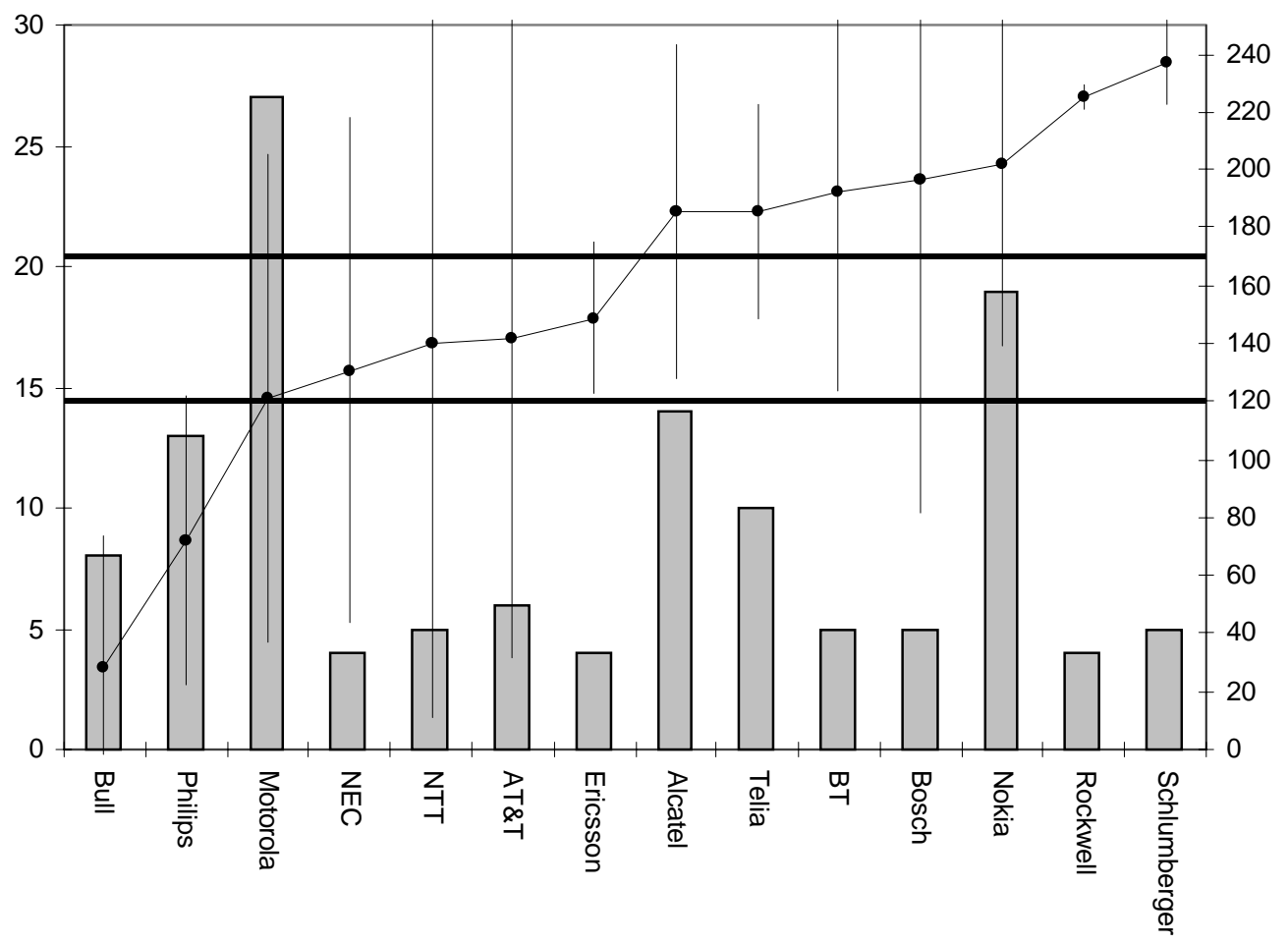

Figure 5. Timing of firms with regard to Essential IPRs in GSM

The results found here largely confirms a more qualitative interpretation of the role of the various firms in the history of GSM. Bull and Philips are clearly earlier than any other firm. All their patents date from the period before the basic choice for the GSM standard was made, and their inventive activity at the time was therefore clearly made without knowledge of the future standard. For Bull, this is related to the phenomenon that we signaled earlier for the encryption field. Bull, through its subsidiary CP8 Transpac, 
held a number of patents related to bankcards, which later became relevant for the GSM standard. Philips was initially strongly involved in the GSM development. But Philips did not patent with a very clear intention to exploit essential IPRs once the standard was established, as is illustrated by the fact that it made the licenses for its most valuable patents (the GSM speech coder) available at no costs.

Motorola has its mean timing value right at the point in time when the standard emerged. Motorola was the only non-European firm that was allowed to participate in the GSM project and one of the first non-European companies to enroll in the ETSI. The firm owed this special position to its significant share in the European supply market for first-generation mobile telephony and mobile radio systems, and its extensive European research and production facilities. As we have already argued above, however, its strategy turned out to be rather different than those of the other suppliers involved (see also Granstrand, 1999).

Motorola had the advantage that it already had some of its work from the pre-standard period laid down in essential GSM patents. But unlike Philips and Bull, it turned this advantage into a strong position after the standard had been decided upon. Where other firms refrained from patenting once the basic technical decisions were taken (i.e., during the early phases of the development period), Motorola intensified its patenting activities. In parallel with the gradual work of drawing up the standard and early product development, Motorola applied for numerous patents that turned out to be essential to the standard. It was even accused of stealing ideas of others and applying for patents on them subsequently (Granstrand, 1999, p. 204). Others, in contrast, were also highly involved in the standardization work but did not apply for patents. They were still stuck to the traditional role of IPRs in telecommunications, and believed there was a 'Gentlemen's agreement', in which 'the developers were generous to each other when it came to potential patents" (Granstrand, 1999, p. 204). The licensing strategy that Motorola adopted once GSM products came to the market showed that this firm had two aims with its intensive patenting activities. First, its licenses enabled it to prevent GSM from being adopted in other world regions in which it had different interests. Second, it could set specific license conditions, such as crosslicensing, enabling access to other firms' technology and dictating the structure of the supply market. 
There are four other companies with patenting activity concentrated in the second period (1987-1991): NEC, NTT, AT\&T and Ericsson (Orbitel). It is striking that the majority (3 out of 4) of these companies is non-European, and that they are all small in terms of the total number of patents. In addition, for NEC, NTT and AT\&T, the patents were not primarily aimed at securing a strong position in GSM. The patents owned by these companies were primarily developed for application in other mobile telephony standards such as D-AMPS and PDC, and just happened to be essential to GSM as well. In fact, none of these companies showed particular interest in the GSM standard at the time. NTT and AT\&T were planning to use different technologies in their home markets. Although NEC did show some interest in developing GSM terminals (NEC announced GSM products both at the Telecom 91 and CEBIT 92 fair), its interest in this market seems to have waned afterwards. We thus conclude that the in period right after the decision for the basic GSM standard had been taken, Motorola was able to build up a strong position in essential patents, with other firms lagging behind considerably.

In the third period, several of the 'lagging behind' companies strongly increased their inventive activities and the patenting thereof. Especially Nokia and Alcatel were able to gain a large portfolio of essential patents in GSM. For these two companies, the 'Gentlemen's agreement' not to patent inventions that was in force during the period 1987-1991 was not the most important reason behind their relatively late entry in the patenting field. For Nokia, the main reason is the fact that up to the early 1990s, mobile telecommunications were only a small activity of this firm. In fact, telecommunications and electronics played only a minor role in Nokia up till this period, and strategic research did not have a very high priority. For Alcatel, the explanation is rather different. Alcatel and its predecessors (of which SEL from Germany is of particular importance here) have been very active in $R \& D$ for digital mobile telephony systems. Their first projects date from around 1981 (e.g., the government-subsidized 'Autotel' study from 1981). The Alcatel technology for mobile communications became the basis for the German-French proposal for a standard in the field that was discussed above, and which became rejected in the negotiations. Alcatel was therefore forced to make a technological re-start, in which the company had to 
focus on product development and not on the more fundamental mechanisms underlying the technology. The data show that despite this late re-entry, Alcatel made up its lag with an impressive range of patents that turned out to be essential to new GSM services.

Going back to our main research question on the determinants of market dominance, what can we say about the relationship between the numbers of essential IPRs that a firm holds, and the question of whether or not it belongs to the 'dominant five' of Table 1? Motorola, Alcatel and Nokia are the three firms that hold the most essential IPRs according to Figure 1. Thus, for these three firms, the evidence is consistent with the hypothesis that market dominance is (at least partially) caused by the possession of essential IPRs. However, there are two firms among the dominant five (Siemens and Ericsson) that do not hold large amounts of essential IPRs. Also, Philips and to a lesser extent Telia and Bull have a relatively large amount of essential IPRs, but do not enter the group of five dominant market players. How can we explain these cases in which the link between ownership of essential IPRs and market shares is less clear?

Ericsson's weak patent position can be explained by the relative lack of importance that was given by the company to IPRs in the 1980s and early 1990s (see, e.g., Granstrand 1999). Although GSM was actually based on a proposal by Ericsson, the firm holds only 4 essential patents, and all of these were not developed within Ericsson itself but became its property when Ericsson bought the British firm Orbitel. The weak patent position of Siemens is explained by the fact that this company initially chose not to be involved in the GSM project at all. It entered the field as late as 1987 and then decided it would give priority to product development instead of R\&D aimed at the fundamental mechanisms underlying GSM. As is evident from Table 1, this led to a strong focus on the production of GSM switches. Obviously, these two issues explain why Ericsson and Siemens did not build up a strong position in essential IPRs, but they do not address the issue as to how these firms were able to enter the group of five dominant market parties. We will postpone this issue until the next section, where we introduce data on strategic technology agreements.

The bad market position of Philips in Table 1 is at contrast with the relatively strong position in terms of the number of essential patents in Figure 1. This can be explained by the decision of Philips to 
withdraw fully from the GSM field in the early 1990s, i.e., during a still relatively early stage of the market. At the time, the substantial research and product development activities carried out by Philips' German subsidiary PKI (which was the major source of Philips' activities in mobile communications) lead to large losses. The corporate Philips management did not regard telecommunications as one of its core activities at the time, and decided it was no longer willing to accept the losses incurred in these activities. PKI was thus forced to withdraw fully from the GSM industry, regardless of the fact that PKI had recently succeeded to win a substantial amount of infrastructure orders (Metze, 1991, p. 297-198). Years later, Philips tried to enter the top-3 in the GSM handset market by force, but failed.

Telia and Bull are the other major firms in terms of patenting that do not hold substantial market share. The specific character of both firms provides a reasonable explanation for this discrepancy. Bull got involved in the development of GSM by accident, because its patents on bankcards turned out to be useful for SIM cards. By nature of this product, Bull never took an interest in producing GSM equipment, but instead licensed out its technology. Telia still is essentially an operator, and hence not primarily interested in manufacturing of equipment either.

We are thus left with the impression that there may indeed be a relationship between a strong position in the ownership of essential IPRs and a dominant market position, but that this is certainly not a relationship without exceptions. Although we are able to explain in a reasonable way why some firms that hold many essential IPRs did not become dominant market parties, we have not yet been able to explain how other firms that did become dominant market players (Siemens and Ericsson) were able to do this without owning a large number of essential IPRs. As we will argue in the next section, the answer can be found in the field of strategic technology agreements.

\section{Strategic technology agreements in GSM}

The data on strategic alliances used in this paper are based on the MERIT-CATI database. We selected from this database the 60 strategic technology alliances that are related to GSM technology. The expression inter-firm cooperation is used to refer to those cooperative agreements between partners that 
are not connected through (majority) ownership at the outset of the period under study. As it happens, some of the firms in our analysis are merged or taken over by other firms in the sample during the period under study (e.g., the above example of Orbitel that gets taken over by Ericsson). In principle, when this happens, we will still treat these firms as separate entities, but make separate calculations for the situation where the two firms are merged in the alliances data.

In this paper we will limit our analysis to technology inclined agreements. In order to safeguard the strategic element in our sample we will study only those alliances that are undertaken for strategic reasons. We will refer to alliances as being strategic if they can reasonably be assumed to effect the longterm product market positioning of at least one partner. Because alliances between government or academic institutions and private companies are often undertaken for different reasons than the alliances between two or more private companies (see e.g. Haklish, 1986), we will restrict our attention to those alliances that are established between private companies. For the same reason we do not pay attention to government initiated or EC-wide R\&D cost-sharing programs such as ESPRIT, EUREKA or JESSI.

Figure 6 shows the cumulative total number of newly established strategic technology alliances in the GSM market (right axis), along with the cumulative number of essential patents that were the subject of analysis in the previous section (left axis). During the second half of the 1970s and early 1980s cooperative activity remained at a rather modest level in the GSM sector. It was not until the late1980s that the rise in the number of alliances really took off. This take-off took place largely in parallel with the steady increase in the number of essential patents (priority date), which indeed suggests a close relationship between the two variables. Apart from two years of stabilization in 1990 and 1995, growth in the number of alliances persisted until the end of the period. Thus, strategic alliances seem to have become an essential vehicle for technology transfer in the GSM market. 


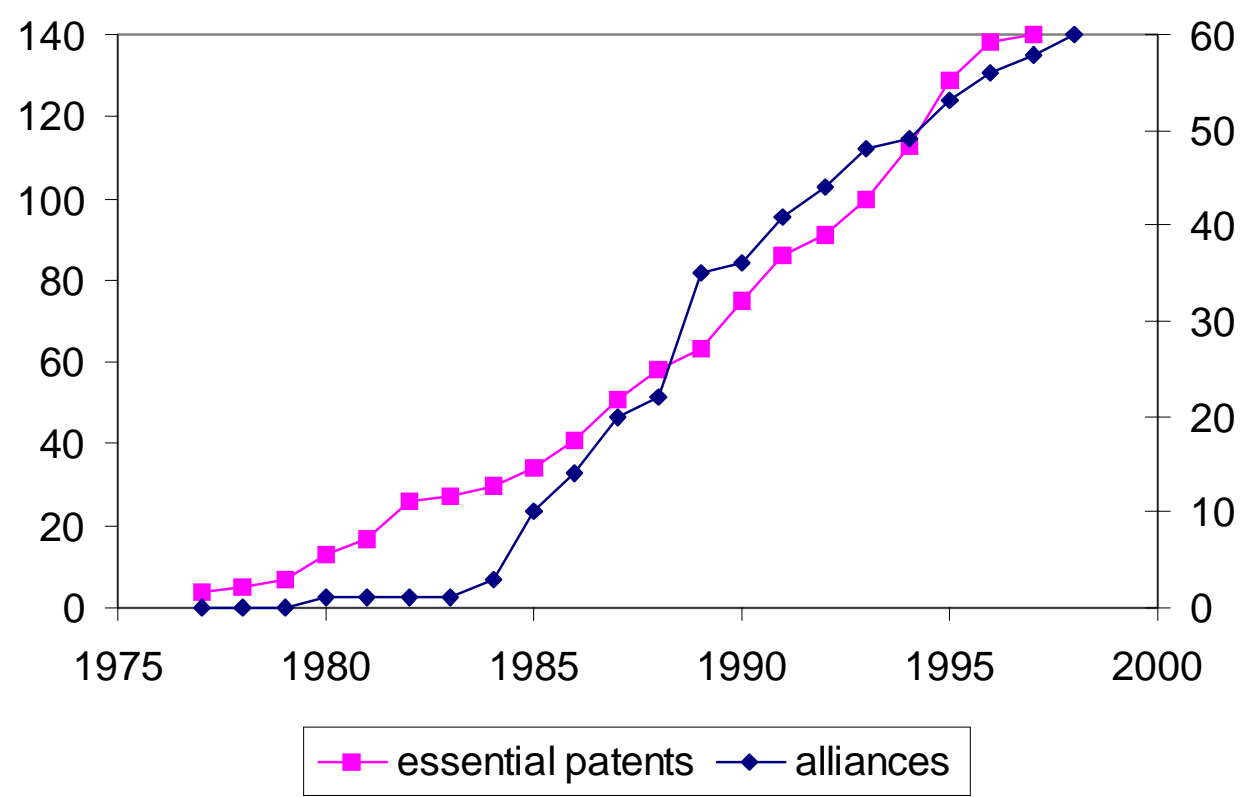

Figure 6. The cumulative number of strategic alliances and essential patents in GSM

After having identified the basic trends in technology partnering, we will now turn to the evolution of cooperative networks. Our main goal is to study the changes in the overall structure of the alliances network over time, and to study the emergence of focal players in the co-operative networks of the GSM sector.

The use of network analysis as a tool to analyze complex social systems was introduced in the 1970s (see e.g. Burt, 1976, Freeman, 1979) and further developed in the 1980s (see e.g. Bonacich, 1987). As argued by Nohria $(1992$, p. 2) “... network analysis has grown from the esoteric interest of a few mathematically inclined sociologists to a legitimate mainstream perspective". Network analysis can be used to analyze complex flows of information, and the simultaneous analysis of all the relationships between individual organizations may result in the description of a social system that closely resembles the structure of a specific organizational field (Barley et al. 1992).

The 60 strategic alliances in our sample contain a total number of 72 firms. The basic source of information for the network analysis in this paper is the adjacency matrix. An adjacency matrix is a matrix 
in which the cells contain the number of direct links between the various companies. The cell value $a_{i j}$ is therefore equal to the number of alliances in which both company $i$ and company $j$ are involved. Because the alliance data do not have a direction, the adjacency matrix in this paper is symmetric. Moreover, we will dichotomize the matrix by re-coding all positive values to 1 .

Not all parts of the large 72 firms network are connected. In total, there are 11 unconnected components in our network, four of which are in fact pairs of firms. Among the other 7 components is one large sub network, and 6 small networks are found. The largest of the small sub networks has five members. The large sub network has 48 firms. We will focus the analysis exclusively on the large sub network of 48 firms. This network contains all the major players in the field.

For a graphical representation of the alliances network, we make use of a statistical technique that is known as non-metric Multidimensional Scaling (MDS). MDS offers scaling of similarity data into points lying in an X-dimensional space. The purpose of this method is to provide co-ordinates for these points in an $\mathrm{N}$-dimensional space (with $\mathrm{N}<\mathrm{X}$, and usually $\mathrm{N}$ equal to 2 or 3 ), such a way that distances between pairs of points fits as closely as possible to the observed similarities.

Figure 7 displays a graphical impression of the network. The center of the network seems to lie somewhat right of the center of the picture, largely comprising the circle Matra-Bosch-Alactel-SELNokia-Ericsson. Around this dense core of the network, there are many firms with only a single link to one of the firms in the core. There are two sub networks in the graph that are loosely connected to the core. These are the 'chain' Cable \& Wireless (C\&W) - Mannesmann - Pacific Telesis (PAC-TELS) - NEC in the center top of the graph, and the densely connected left upper corner. The latter is a set of largely American operators, which is connected to the core through a chain in which Racal, Plessey and BellSouth play a pivotal role. 


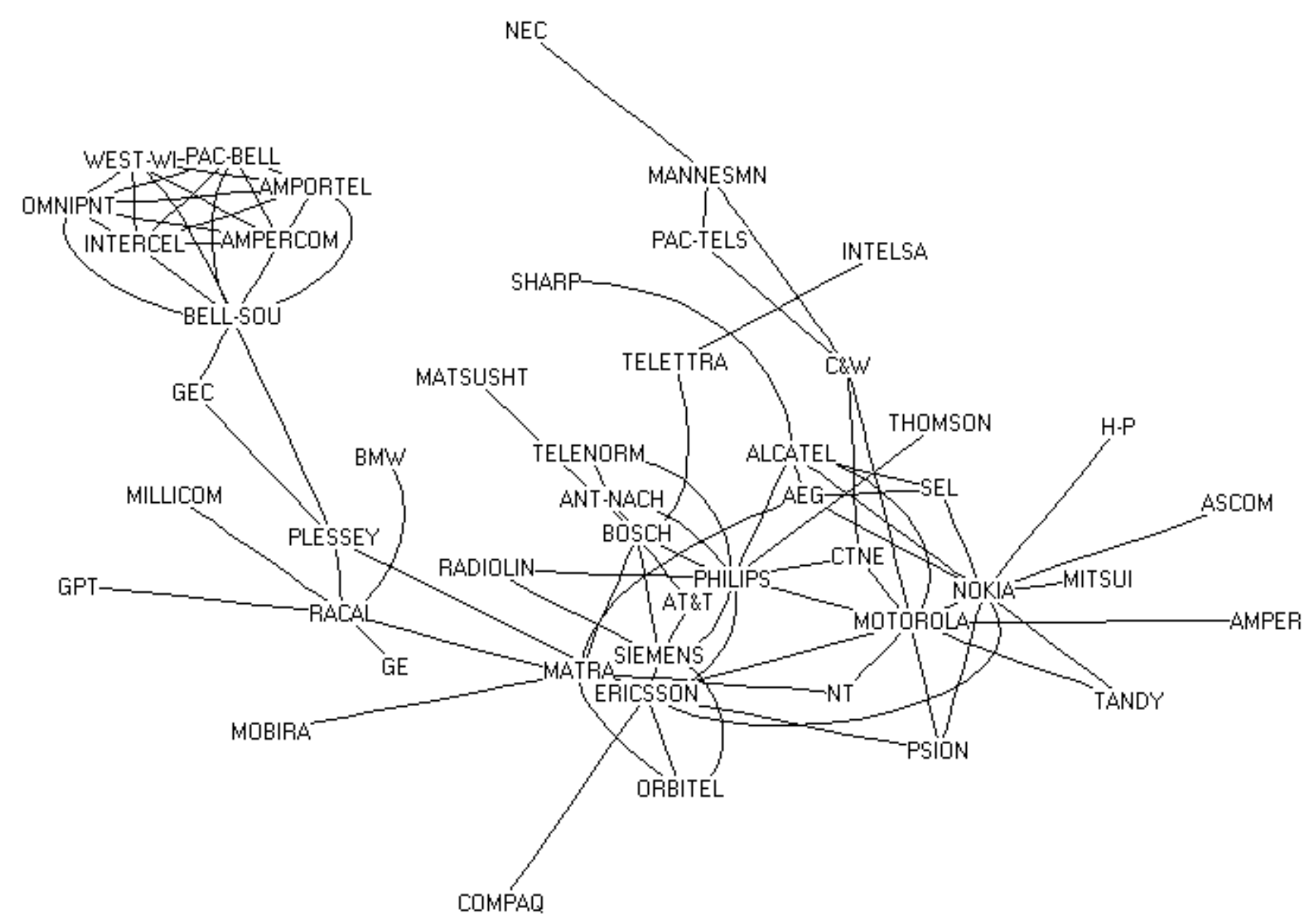

Figure 7. The strategic technology alliances network in GSM, 1980-1998 
We proceed by analyzing in more detail the role of individual firms in this network. For this, we will use the concept of 'network centrality', which is in a way a measure of the importance of particular players. Centrality in a network context refers to the importance of a specific organization for the overall structure of a network. Centrality in information networks was first introduced by Bavelas in 1948 to assess the relationship between centrality and power within networks (Freeman, 1979). Advances in graph theory in later years have significantly broadened the use of centrality measures as a tool to assess the importance of a specific point (or actor) in a network. In this paper we will use three basic measures of centrality as put forward by Freeman (1979): degree centrality $\left(C_{D}\right)$, betweenness centrality $\left(C_{B}\right)$ and closeness centrality $\left(C_{C}\right)^{17}$

The most straightforward measure of centrality is the so-called degree centrality $\left(C_{D}\right)$. Degree centrality is measured by summing the total number of actors to which a specific player is adjacent in the matrix. The degree of an actor is therefore equal to the total number of direct links of a particular actor to other actors. The measure is standardized by dividing through by the maximum possible number of connections ( $n-1$, where $n$ is the number of firms, i.e., 48). In formal terms, degree centrality of firm $k$ is equal to (remember that $a$ is a binary variable):

$$
C_{D}(k)=\sum_{i} \frac{a_{i k}}{n-1}
$$

Actors that are represented by a high degree of degree centrality share the ability to access a large stock of potential information sources.

The second centrality measure that was put forward by Freeman is the so-called betweenness centrality $\left(C_{B}\right)$. Betweenness refers to the number of times an actor is located on the shortest path ('geodesic') between two other actors. ${ }^{18}$ If a certain actor is directly linked to two other actors who are not directly linked to each other, then the first actor is said to be 'between' the two other actors. In formal terms:

\footnotetext{
${ }^{17}$ See also, Duysters and Vanhaverbeke, 1996
} 
$C_{B}(k)=\sum_{i} \sum_{j<i} \frac{g_{i j}(k)}{g_{i j}}$,

where $g_{i j}$ represents the number of geodesic paths between $i$ and $j$, and $g_{i j}(k)$ is the number of these paths on which firm $k$ is present.

In an information network a company that has a high degree of betweenness centrality has a potential to control the flows of information between those other companies (Freeman, 1979; Knoke and Kuklinski, 1982). In this paper we will therefore use $C_{B}$ as an indicator of the ability to control flows of information within a network.

Finally, closeness centrality $C_{C}$ is associated with the distance between the location of a certain player and the location of the other players in the network. Distance is measured as the length of geodesics (number of firms on the geodesic). Formally, closeness centrality is defined as follows:

$C_{C}(k)=\frac{n-1}{\sum_{i} d g_{i k}}$,

where $d g_{i j}$ represents the length of the geodesic from firm $i$ to firm $k$.

If a company has high closeness centrality in a network, this means that it is close to most of the other players, and hence is able to avoid the control of others (Freeman, 1979).

\footnotetext{
${ }^{18}$ For example, to move from Hewlett-Packard (H-P) to Psion in the shortest way possible in the network in Figure 8 , one would have to 'move through' Nokia. Nokia is thus on the geodesic from Hewlett-Packard to Psion.
} 
Table 2. Network centrality scores, 26 firms with highest degree centrality

\begin{tabular}{|c|c|c|c|c|c|c|c|}
\hline \multirow[b]{2}{*}{ Company } & \multirow[b]{2}{*}{ Motherfirm } & \multicolumn{3}{|c|}{ Original network } & \multicolumn{3}{|c|}{ Network with mergers } \\
\hline & & $C_{D}$ & $C_{B}$ & $C_{C}$ & $C_{D}$ & $C_{B}$ & $C_{C}$ \\
\hline Philips & & 23.4 & 25.5 & 42.7 & 23.7 & 18.9 & 42.7 \\
\hline Ericsson & & 21.3 & 51.6 & 47.5 & 23.7 & 35.0 & 48.7 \\
\hline Nokia & & 21.3 & 18.0 & 39.2 & 26.3 & 19.8 & 42.7 \\
\hline Motorola & & 21.3 & 25.5 & 43.5 & 26.3 & 29.0 & 48.7 \\
\hline BellSouth & & 17.0 & 22.8 & 29.9 & 21.1 & 13.9 & 34.5 \\
\hline Bosch & & 14.9 & 13.2 & 33.6 & 13.2 & 5.6 & 33.3 \\
\hline Siemens & & 14.9 & 5.5 & 38.8 & 15.8 & 4.1 & 38.4 \\
\hline Matra & & 14.9 & 10.3 & 38.2 & 15.8 & 6.2 & 39.2 \\
\hline Racal & & 12.8 & 16.5 & 36.7 & 15.8 & 17.0 & 38.4 \\
\hline Alcatel & & 12.8 & 7.1 & 35.9 & 13.2 & 7.0 & 38.4 \\
\hline American Personal Communication & & 12.8 & 0.0 & 23.7 & 15.8 & 0.0 & 28.8 \\
\hline American Portable Telecom & & 12.8 & 0.0 & 23.7 & 15.8 & 0.0 & 28.8 \\
\hline Intercel & & 12.8 & 0.0 & 23.7 & 15.8 & 0.0 & 28.8 \\
\hline Omnipoint & & 12.8 & 0.0 & 23.7 & 15.8 & 0.0 & 28.8 \\
\hline Pacific Bell & Pacific Telesis & 12.8 & 0.0 & 23.7 & & & \\
\hline Western Wireless Corporation & & 12.8 & 0.0 & 23.7 & 21.1 & 13.9 & 34.5 \\
\hline AEG & & 8.5 & 1.5 & 33.1 & 7.9 & 0.1 & 33.0 \\
\hline Intelsa & Ericsson & 8.5 & 28.9 & 37.9 & & & \\
\hline Cable \& Wireless & & 8.5 & 12.2 & 32.0 & 10.5 & 19.8 & 40.0 \\
\hline $\mathrm{AT} \& \mathrm{~T}$ & & 6.4 & 0.0 & 31.8 & 7.9 & 0.0 & 31.1 \\
\hline $\begin{array}{l}\text { Compañia Telefónica Naçional de } \\
\text { Espagna }\end{array}$ & & 6.4 & 2.0 & 33.8 & 7.9 & 3.0 & 38.8 \\
\hline SEL & Alactel & 6.4 & 0.0 & 31.1 & & & \\
\hline ANT Nachrichtentechnik & Bosch & 6.4 & 0.2 & 31.5 & & & \\
\hline Orbitel & Ericsson & 6.4 & 0.0 & 35.1 & & & \\
\hline Mannesman & & 6.4 & 4.3 & 24.7 & 7.9 & 5.3 & 31.4 \\
\hline Psion & & 6.4 & 0.0 & 36.7 & 2.6 & 0.0 & 33.0 \\
\hline
\end{tabular}

Table 2 gives the scores of the most central companies on each of the three measures. Overall, four companies tend to be particularly more central in the alliance networks than others; Philips, Ericsson, Motorola and Nokia. ${ }^{19,20}$ The latter three are included in the group of five dominant firms in Table 1

\footnotetext{
${ }^{19}$ BellSouth is a peculiar case, also with relatively high centrality, but position is largely the result of the pivot function between the left-upper corner and the rest of the network in Figure 8.

${ }^{20}$ The last three columns in Table 2 give the centrality measures for a situation where the mother-daughter relations between firms in the sample have been taken into account. In this case, for example, Orbitel is merged into Ericsson (similar for all the other firms that are identified as daughters in Table 2), and all of Orbitel's alliances are ascribed to Ericsson instead. As is shown by the results in Table 2, this does not change the relative order of the top-4, and therefore the conclusions, dramatically.
} 
above, while the absence of Philips in that group has already been explained above. Alcatel and Siemens, the other two firms from the top-5 market players, do not rank at the very top of Table 2 , although their position is in the top-10 of Table 2. Also, three of the four dominant network firms hold strong positions in essential IPRs. Among the four ' network giants', Philips stands out in terms of its number of alliances (degree centrality). As described above this implies a high ability to access a large stock of potential information sources. Philips can be referred to a central source of information, at least in terms of the number of other players it is in contact with.

Although Philips was vastly dominating the network for a long time (at the end of the eighties its degree centrality was almost twice as high as the degree centrality of the firms in the positions 2-5) its dominance has started to slip over time. This is displayed in Figure 8, which gives for the (network) dominating four firms the evolution of the network centrality measures over time (calculation for the cumulative set of strategic alliances up to and including the year on the horizontal axis; 1998 corresponds to Figure 8 and Table 2). The first part of the figure shows how Philips gradually lost its central role in terms of degree centrality, and how the other three firms catch up. What is most the interesting feature in Figure 9 with regard to our research question is that Motorola is the first to catch up, i.e., during the period immediately after the acceptance of the basic GSM standard (1988 - 1992). Nokia and Ericsson catch up much later, i.e., towards the end of the period.

This relative timing of the emergence of strong network positions is in line with the findings on essential IPRs in Figure 5. There it was shown that Motorola's patent position was built up earlier than that of Nokia, and that the Philips dominant patent position was built up exclusively during the earliest GSM phase. Obviously, Ericsson is an exception to the close connection between ownership of essential IPRs and a strong network position. 

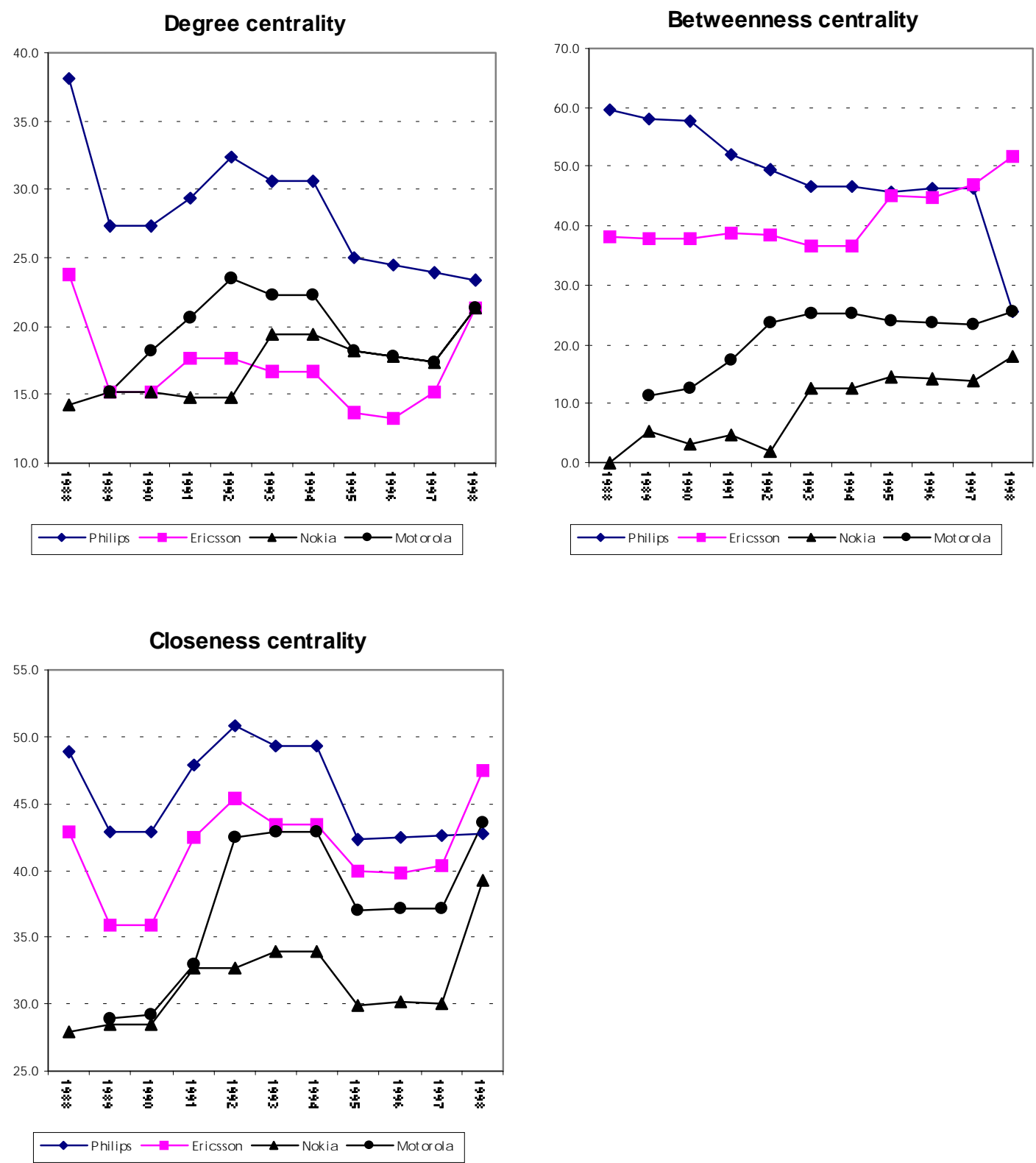

Figure 8. The evolution of network centrality for the four most central firms in the network

The picture is somewhat different for the two other, more sophisticated measures of centrality. The only thing that the dynamic movement of these indicators clearly shares with the first one (degree centrality) is the increase of the score of Motorola during the late 1980s and early 1990s. The movement and relative position for Ericsson and Nokia differs quite a bit between the three parts of Figure 8. The movements of 
these two firms are rather erratic, and jumps or falls are mostly related to a single year, i.e., one or two isolated alliances.

Thus, while it is possible to argue for three of the four dominant network players that their position in the network is based on ownership of essential IPRs, Ericsson emerges as the major exception to this relationship. Despite its relatively weak position in terms of essential patents, Ericsson is a very well positioned company in the GSM network. Because of its strategic position, it is not dependent on other companies for its information flow, and it holds a position as a gatekeeper for the flow between other companies in the network. We attribute this exception to the fact that the basic GSM technology is based on an Ericsson proposal, as pointed out above. Consequently, this company had a technological head start. Furthermore, during the period of GSM product development (1988 - 1992), Ericsson set up numerous co-operations with suppliers from different countries, thus opening up entry into many national markets (Meurling and Jeans, 1994). Thus, although Ericsson did not emerge with very many essential IPRs, it definitely was a smart networker.

This purely quantitative analysis of the strategic technology agreements network does not, however, tell the complete story with regard to the importance of networking, although in combination with the story we have told in connection with Figure 5 it does provide an important hint. The crucial aspect that remains hidden in the quantitative representation of the network is the special importance of a number of strategic alliances, more specifically a limited number of bilateral cross-licensing agreements between Motorola and some other firms, all of which together (including Motorola) have become the top5 dominant market players in Table 1 . These agreements are part of the agreements that initiated the catch-up of Motorola in terms of network centrality in the late 1980s and early 1990s. The reason why these agreements have become so important is the strong position of Motorola in the field of essential IPRs as has been shown in Figures 1 and 5. Firms that were not allowed access to this set of Motorola essential IPRs have not been able to enter the market in a major way. 
The catch-up of Motorola in terms of networking position was thus largely based on the aggressive patenting strategy the company had followed during the early phase of development of the GSM standard. The strategic agreements Motorola was able to strike in this way were of prime importance to the company, which was the only non-European firm that was involved in the development of the standard. Although this different national background could be seen as a certain disadvantage, it also, however, implied some advantages. ${ }^{21}$ Specifically, companies from the US at the time were better aware of the value of IPRs, especially after the demonstration effect of the lawsuits of Kodak vs. Polaroid, and the successful defence of Texas Instrument's 'Kilby' patent before court, both in 1985/1986. ${ }^{22}$ This resulted in a very pro-patent attitude of US companies, and Motorola was among the American companies with a relatively aggressive IPR policy. Additionally, Motorola always showed a tradition of having to fight hard for its market share. In its domestic telecommunications supply sector, it had to compete with AT\&T's vertically integrated manufacturing company, whereas in the foreign telecommunications sector it had to fight against procurement practices that favoured national suppliers. Motorola is also active in electronics and microprocessors, and in both these markets it had strong (domestic) competitors (e.g. Intel). Finally, Motorola's (initial) lack of market share in Europe and its fears that GSM contracts would be awarded to European suppliers contributed to its aggressive GSM licensing practices. ${ }^{23}$

The inclusion of Nokia and Alcatel in the bilateral cross-licensing agreements with Motorola is in line with the relatively strong position of these firms in the technological field, as indicated by their ownership of substantial amounts of essential IPRs. For other firms with a strong position in essential IPRs (Philips, Bull, Telia), it has already been explained why they were not interested in manufacturing GSM equipment, and the same reasons apply to the question why these firms did not enter into

\footnotetext{
${ }^{21}$ See Iversen (1999) for a more elaborate treatment of many of the points made in this paragraph with regard to Motorola.

${ }^{22}$ In Polaroid's infringement suit against Kodak, the latter had to pay almost US\$ 1 billion for damages and was barred from the instant-film camera market. With its so-called 'Kilby' patent, Texas Instrument was able to demand high royalty fees to all companies manufacturing integrated circuits. See Hall \& Ziedonis, 2000, p. 11-12.

${ }^{23}$ Iversen (1999, p. 94).
} 
agreements with Motorola. The inclusion of the other two parties in the bilateral cross-licensing deals, Siemens and Ericsson, need some more explanation, however.

Motorola had strong experience in developing base station products and mobile terminals, but did not have a switching platform on which GSM switching products could be based. Thus, it tried to strike alliances with other suppliers that did have such a platform. The firm was thus in need for a partner in order to be able to offer complete systems on the market. This is how Siemens was able to enter the deal with Motorola. As is evident from Table 1, Siemens is specialized strongly in switching. Ericsson succeeded in securing a cross-license agreement with Motorola by virtue of having developed the selected technical proposal for GSM. This, and its 'smart networking' behavior described above, secured this firm an indispensable position in the network. Additionally, Ericsson was already one of the largest global players on the market for analogue mobile telephony, and, without doubt, would have done anything within its capabilities to fight an eventual refusal of Motorola to license IPRs.

\section{Conclusions and discussion}

The GSM case provides an interesting example of how (essential) IPRs ownership and alliance networks influence each other, and how both of them affect market structure and market shares. We have shown how the GSM market has become dominated by five major firms in the late 1990s: Ericsson, Nokia, Siemens, Motorola and Alcatel. Together, these five firms control more than $85 \%$ of the European GSM market (which is the largest in the world). We have shown how two of these firms (Motorola and Nokia) are characterized by both a strong position with regard to the ownership of essential IPRs and a central position in the network of strategic technology agreements in mobile communications. Two other firms score relatively high on at least one of these two variables: Ericsson with regard to network centrality (but not essential IPRs) and Alcatel with regard to essential IPRs (but not network centrality). Siemens has neither a strong position in essential IPRs not in network centrality. 
The relationship between market power (inclusion in the top-5 equipment suppliers) and the two variables of our main interest (essential IPRs and network centrality) is thus at best a positive one with some major exceptions. One is thus tempted to conclude that a pure quantitative analysis of the relationship between these three variables leaves important parts of the story of how these five companies came to dominate the GSM market untold. The key to understanding these 'missing links' largely lie in the activities of one company, Motorola, during the period just after the technical GSM standard had been set.

We identified three periods in the history of GSM. The first is a pre-standard period (until February 1987). In this period, there was huge technological uncertainty on which of the competing technologies would be adopted as the standard. Thus, what later became 'essential' IPRs (patents) to the GSM standard from this period, were at the time just one of a number of options for the future. A high number of (with hindsight, essential) patents during this period did not necessarily lead to later dominance in the industry, as is shown by the evolution of the market position of Motorola and Philips.

Philips was the company with most essential patents from the pre-standard period. However, it did not play a major role in the production and sales of GSM equipment afterwards, mainly because of strategic choices of the management. Its strong early position in terms of technology and patents did, however, lead to early dominance of the technology alliances network. But this position waned when other players started to develop the GSM standard later on.

Motorola, on the other hand, was able to use its relatively strong position in the pre-standard age in the period in a more vigorous way afterwards. During the period until 1991, which we characterize as the period in which the basic standard was developed, Motorola built up a strong portfolio of essential patents in GSM. Other firms, including those in Europe most involved with the development of GSM (e.g., Ericsson, Siemens, Alcatel), did not follow an aggressive patenting strategy, basically because they were used to manners of conduct in a pre-liberalization European market (Ericsson), or simply because they did not have the inventions yet (Alcatel, Nokia).

By using the negotiation power that came with its patent portfolio, Motorola could dictate its licensing conditions to all firms. The company thus imposed a market structure by conducting exclusive 
cross-license agreements with a selected number of other parties on the market. These parties were selected because their IPRs were valuable to Motorola (not only essential patents, but also others), or because their product line complemented that of Motorola. Also Motorola took the position of firms in the alliance network into account when selecting its cross-licensing partners (Ericsson). As a result, the importance of Motorola in the network of strategic alliances increased drastically in the late 1980s.

Firms that took part in the cross-licensing agreements (i.e. Ericsson, Nokia, Siemens, Motorola, and Alcatel) dominate the market for GSM infrastructure and terminals. They hold well above $85 \%$ of the total market, which is estimated to be worth more than 100 billion US\$. ${ }^{24}$ Only five years after the first commercial products were introduced on the market, other companies, including those from the Far East and from the American continent, gradually succeed in capturing some part of this huge market. In the field of technology and essential patenting, this process of catching-up took the form of a number of additions to the standard in the form of more enhanced equipment or services. We denote this as the third phase in the history of GSM. This is the period when some of the major European firms (most notably Alcatel, Nokia and Telia) took out large amounts of essential patents in GSM. This is also the period during which Nokia and Ericsson greatly improved their position in the alliances network.

The play with the essential GSM IPRs, and the strategy of Motorola in particular, dramatically changed standardization processes in the telecommunications industry. From 1992 on, many firms have intensified their patenting activities, hoping to obtain essential IPR for future standards or additions to existing standards. Where IPR was considered a non-issue in this sector for many decades, it is now among the main issues to be resolved for any new standard, as has recently been shown with the standardization of third-generation mobile networks. ${ }^{25}$ Thus, within the major telecommunications firms, managers seem to have learned their lesson on the strategic importance of IPRs. However, at the level of

\footnotetext{
${ }^{24}$ Note 1, Communication from the Commission on strategy and policy orientations with regard to the further development of mobile and wireless communications (UMTS), COM(97)513, Brussels.

${ }^{25}$ For example, the European third-generation mobile standard, UMTS (Universal Mobile Telecommunications System), has been threatened to be blocked for over one years by the US firm Qualcomm. This firm owns essential patents to the CDMA technology that is employed in UMTS.
} 
the public interest in standard setting, the increasingly sharp negotiations about essential IPRs are not necessarily a positive development.

\section{References}

Archibugi, D., M. Pianta, 1996, Innovation surveys and patents as technology indicators: the state of the art. In: Innovation, patents and technological strategies, Paris: OECD.

Barley, S.R., J. Freeman and R.C. Hybels (1992), 'Strategic Alliances in Commercial Biotechnology', in N. Nohria, and R.G. Eccles (eds), Networks and Organizations: Structure, Form and Action, Harvard Business School Press, Boston, Mass.

Bavelas, A. (1948), 'A mathematical model for group structures', Human Organization, 7: 1630. Op. Cit. L.C. Freeman, 'Centrality in Social Networks: Conceptual Clarification', Social Networks, 1:21539.

Bekkers, R.N.A. \& Liotard, I. (1999). 'The tense relation between mobile telecommunications standards and IPR', European Intellectual Property Review (1999) Issue 3, 110-126.

Boisot, M.H. (1998). Knowledge Assets. Securing competitive advantage in the information economy. Oxford: Oxford University Press.

Bonachich, P. (1987). 'Power and centrality: a family of measures'. American Journal of Sociology, pp. 1170-1182.

Brooks, J. (1975). Telephone: The first hundred years. New York: Harper \& Row.

Burt, R.S. (1976). 'Positions in Networks', Social Forces, 12, pp. 328-383.

Castells, M. (1996). The rise of the network society. Oxford, Blackwell.

Cattaneo G. (1994). 'The making of a Pan-European network as a path-dependency process: The case of GSM versus IBC (Integrated Broadband Communications) network', in G. Pogorel (ed.). Global Telecommunications Strategies. Amsterdam: Elsevier Science.

Chapuis, R. \& Joel, A.E., Jr. (1990). Electronics, computers and telephone switching: A book of technological history. Amsterdam: North-Holland publishing company.

Duysters, G., W. Vanhaverbeke, Strategic Interaction in DRAM and RISC technology: A Network Approach, Scandinavian Journal of Management, (1996), vol 12, No 4, pp. 437-461.

ETSI (1998). Intellectual Property Rights (IPRs); Essential, or potentially essential IPRs notified to ETSI in respect to ETSI standards (Version SR000314 V 1.3.1, 1998-6).

Freeman, L.C.. (1979). 'Centrality in social networks: conceptual clarification' Social Networks, 1, pp. 215-239.

Garrard, G.A. (1998). Cellular communications: Worldwide market development. Norwood, MA: Artech House. 
Good, D. (1991). 1992 and product standards: A conflict with intellectual property rights?' European Intellectual Property Review, Issue 11, 398-403.

Granstrand, O. (1999). The economics and management of intellectual property: Towards intellectual capitalism. Cheltenham, UK: Edgar Elgar.

Hacklish, C.S. (1986), Technical alliances in the semiconductor industry, Center for Science and Technology Policy, New York University, mimeo.

Hall, B.H. \& Ziedonis, R.H. The patent paradox revisited: An empirical study of patenting in the US semiconductor industry, 1979-1995. Paper presented at the Swedish International Symposium on Economics, Law and Intellectual property, Chalmers University of Technology, Gothenburg, 26-30 June 2000.

Hagedoorn, J., J. Schakenraad, 1993, Strategic technology partnering and international corporate strategies, in: K. Hughes, (ed) European competitiveness, Cambridge University Press, 60-86.

Hansen, O.E. \& Søndergård, B. (1993). Does GSM make sense? An assessment of GSM as an example of Paneuropean technology development. Paper presented at the European Conference of International Telecommunications Society, Götenborg, Sweden, 20-22 June 1993.

Iversen, E. (1999). Standardisation and intellectual property rights: Conflicts between innovation and diffusion in new telecommunications systems. In Jakobs, K. (Ed.). Information technology standards and standardization: A global perspective (pp. 80-101). Hershey, PA [etc.]: Idea Group Pub.

Knoke, D. and J.H. Kuklinski (1982), Network Analysis, Sage Publications, Newbury Park, London.

Liotard, I. (1999). Normalisation, droits de propriété intellectuelle et stratégies des firmes [Standardisation, intellectual property rights and firm's strategy] (Doctoral dissertation). CREI, University of Paris 13.

Metze, M. (1991). Kortsluiting: Hoe Philips haar talenten verspilde [Short circuit: How Philips wasted its talents]. Nijmegen: Sun.

Meurling, J. \& Jeans, R. (1994). The mobile phone book: The invention of the mobile telephone industry. London: Communications Week International (on behalf of Ericsson Radio Systems).

Noam, E. (1992). Telecommunications in Europe. Oxford University Press.

Nohria, N. (1992), 'Introduction: Is a Network Perspective a Useful Way of Studying Organizations?', in N. Nohria and R.G. Eccles (eds), Networks and Organizations: Structure, Form and Action, Harvard Business School Press, Boston, Mass.

Nooteboom, B., 1999, Interfirm-Alliances: analysis and design, London: Routledge.

Pelkmans, J. (1999). The GSM standard: Explaining a success story. (Draft, to be published)

Wilkinson, S.L. (December, 1991). They're stealing our diamonds: The standards assault on patents. Revue Canadienne de propriete intelectuelle, Vol. 8, No. 2, p., 193-205. 